\title{
Critérios Morfodinâmicos para o Estabelecimento de Limites da Orla Costeira para fins de Gerenciamento
}

\author{
Dieter Muehe \\ Laboratório de Geografia Marinha \\ Departamento de Geografia - UFRJ \\ E-mail: dieter@ufrj.br
}

Recebido 15 de janeiro 2001; revisado 28 de agosto 2001; aceito 5 de setembro 2001

\begin{abstract}
RESUMO
A ocupação do litoral brasileiro, principalmente nas proximidades das grandes cidades, vem se caracterizando por profunda alteração e deterioração da paisagem. Casas e edifícios são construídos nas proximidades imediatas da orla a ponto de estarem sujeitos a risco potencialmente elevado de perda por erosão. A análise das características geomorfológicas e morfodinâmicas do litoral indicam que o baixo gradiente do fundo marinho, principalmente nas regiões Norte e Nordeste, representa uma vulnerabilidade extremamente elevada a uma elevação do nível do mar que, entretanto, é localmente absorvida pela ocorrência de falésias de sedimentos consolidados e por recifes de arenito de praia. Os impactos de uma elevação do nível do mar são considerados para diferentes feições geomorfológicas induzindo respostas de translação, erosão e inundação. Limites mínimos para o estabelecimento de uma faixa de proteção englobando a zona marinha e terrestre são apresentados e comparados com limites estabelecidos em outros países.

O presente artigo resulta de consultoria prestada ao Ministério do Meio Ambiente, por intermédio do Projeto de Gestão Integrada dos Ambientes Costeiro e Marinho (GERCOM), do Programa de Proteção e Melhoria da Qualidade Ambiental, da Secretaria de Qualidade Ambiental nos Assentamentos, no âmbito do Projeto BRA/94-016 - PNUD.
\end{abstract}

Palavras chave: orla, limites, faixa de proteção, nível do mar, erosão costeira, antepraia e Brasil.

\begin{abstract}
The general characteristic of the occupation of the Brazilian coastline in the neighborhood of the main cities is a pronounced deterioration of the environment and of the landscape as also the construction of houses and buildings in the immediate vicinity of the beach in a way that proprieties are strongly endangered by erosion. The analysis of geomorphic and morphodynamic characteristics of the coastline showed that the continental shelf, mainly in the North and South regions, are of an extremely low gradient which results in large retrogradation of the coastline in case of a sea level rise. For instance the typical $50 \mathrm{~m}$ coastal retreat frequently considered for a sea level elevation of one meter are multiplied by a factor of 10 to 15 . Nevertheless, locally the amplitude of the response will be significantly reduced due to the presence of bluffs of sedimentary rocks or due to the occurrence of beach rocks working as wave breakers. The impact of a one-meter sea level rise is considered for different geomorphic features with their responses in terms of shoreline translation, erosion and inundation. Minimum limits for buffer zones are suggested and compared to limits established in other countries.

Present paper is an outcome of a consultancy to the Ministry for the Environment trough the Project of Integrated Management of Coastal and Marine Environments of the Program for Protection and Improvement of the Environmental Quality of the Secretaria de Qualidade Ambiental nos Assentamentos, Project BRA/94/016-PNUD.
\end{abstract}

Keywords: coastline, set-back zonation, sea level rise, coastal erosion, shoreface and Brazil.

\section{Introdução}

A orla costeira, ou simplesmente orla, é a estreita faixa de contato da terra com o mar na qual a ação dos processos costeiros se faz sentir de forma mais acentuada e potencialmente mais crítica a me- dida que efeitos erosivos ou construcionais podem alterar sensivelmente a configuração da linha de costa. Representa também uma faixa na qual a degradação ambiental por destruição da vegetação e construção de edificações se torna extremamente evidentes por modificar, geralmente para pior, a estética da paisagem 
e até mesmo intervir no processo de transporte sedimentar, tanto eólico como marinho, provocando desequilíbrios no balanço sedimentar e conseqüentemente na estabilidade da linha de costa. Assim, tanto no sentido do estabelecimento de uma zona de proteção costeira contra fenômenos erosivos, quanto no de preservação da paisagem, torna-se importante a definição de critérios para a fixação de limites tanto oceânicos quanto terrestres, legalmente aceitos, para que se possa orientar ações de controle e restrição de atividades que venham alterar de forma negativa as características ambientais, estéticas e de acessibilidade à orla.

Nos critérios atuais, o limite de $33 \mathrm{~m}$, dos chamados terrenos de marinha, medido, em direção à retroterra, a partir da baixa mar de sizígia de 1831 , além de ser de difícil determinação, freqüentemente não ultrapassa a largura da berma de praias mais largas. Limites oceânicos sequer são considerados.

Apenas para exemplificar consideremos a situação de uma praia dissipativa no litoral do Rio de Janeiro, exposta a ondas de tempestade com altura na arrebentação freqüentemente superior a $3 \mathrm{~m}$. Nessa praia a adoção de um limite de, por exemplo, $100 \mathrm{~m}$, medido a partir da posição do nível de baixa do mar, ultrapassaria apenas ligeiramente a crista das dunas frontais. Não representaria, por conseguinte, segurança contra eventos associados a mudanças globais, como elevação do nível do mar e intensificação das tempestades. Em vista deste exemplo seria mais razoável o estabelecimento de um limite de $200 \mathrm{~m}$, ou mesmo superior. Este, no entanto, considerando o clima de ondas menos agressivo que o do Sul e Sudeste, poderá ser excessivo para a região Nordeste e Norte, teria porém a vantagem de garantir uma faixa de não edificação e conseqüente preservação da paisagem natural da borda costeira. Por outro lado as regiões Norte e Nordeste tendem a apresentar maior amplitude de resposta erosiva a uma elevação do nível do mar, devido o baixo gradiente de sua plataforma continental, uma variável a ser considerada no estabelecimento do limite terrestre da orla por constituir uma possibilidade real, haja visto o incremento do descongelamento de geleiras durante a década de 90 (Worldwatch 2000) e a tendência histórica de elevação da temperatura atmosférica. Tal consideração não é de aceitação fácil pois os impactos decorrentes desta elevação se manifestam em escalas de tempo (décadas a séculos) superiores aos típicos horizontes de planejamento, sendo muitas vezes mais longos que o conhecimento disponível (Nicholls et al. 1993 apud Nicholls et al. 1995).

2. Critérios Morfodinâmicos de Delimitação da Orla e de Estabelecimento de Faixa de Proteção Costeira
O critério morfodinâmico considera essencialmente a capacidade de mobilização dos sedimentos do fundo marinho por ação das ondas e seu deslocamento ao longo de um perfil perpendicular à costa e a resposta morfológica da porção emersa do litoral aos efeitos de erosão, transporte e acumulação resultante desse processo de mobilização sedimentar.

A amplitude da resposta a esses processos por sua vez depende do clima de ondas e do grau de exposição do segmento costeiro considerado, além das características geológicas do mesmo, podendo-se distinguir entre litorais constituídos por sedimentos não consolidados formando praias e feições morfológicas associadas (cordões litorâneos, ilhas barreira, pontais, planícies de cristas de praia, tombolos), rochas sedimentares consolidadas (falésias) e rochas duras (costões, costeiras).

Quanto ao estabelecimento da largura da faixa de proteção costeira, os critérios adotados consideram a tendência erosiva ou progradacional expressa pela taxa de retrogradação/progradação anual, a retrogradação prevista por efeito de elevação do nível relativo do mar e aspectos estéticos-paisagísticos.

\section{Classificação Segundo a Exposição às Ondas}

A inferência mais simples do grau de exposição, isto é, sem conhecer o clima de ondas, é a utilização da relação entre a inclinação da face praial e a característica granulométrica dos sedimentos expressos em termos de diâmetro médio ou mediano ou em velocidade de decantação, conforme mostra a figura 1.

A classificação de Exposto, Semi-Exposto e Protegido, assim obtida, fornece uma idéia da agressividade do clima de ondas em termos de erosão e da capacidade de mobilização dos sedimentos da zona submarina (antepraia), sem contudo permitir o estabelecimento do limite dessa profundidade. Em termos gerais, a profundidade na qual a mobilização sedimentar se traduz em variações significativas da topografia do fundo, a chamada profundidade de fechamento do perfil, se situa geralmente a menos de $15 \mathrm{~m}$, conforme mostra a figura 2.

A profundidade de fechamento do perfil de praia, em fundos arenosos, a partir do clima de ondas, pode ser determinada pela equação empírica de Hallermeier (1981), onde a profundidade deve ser estabelecida para o nível zero igual a $1 \mathrm{~m}$ acima do nível de baixa mar, considerando desta forma a influência da amplitude da maré que, em locais de macro-maré, poderia indicar um valor acima da baixa mar, caso se tomasse o nível de preamar como referência (Nicholls et al. 1995):

$$
d_{l, 1} \cong 2 \bar{H}_{s}+11 \sigma
$$

onde $\quad d_{l, 1}=$ profundidade de fechamento do perfil (m), (aproximadamente a metade da pro- 
fundidade do limite distal da antepraia) calculado a partir de um ano de observações de altura de onda.

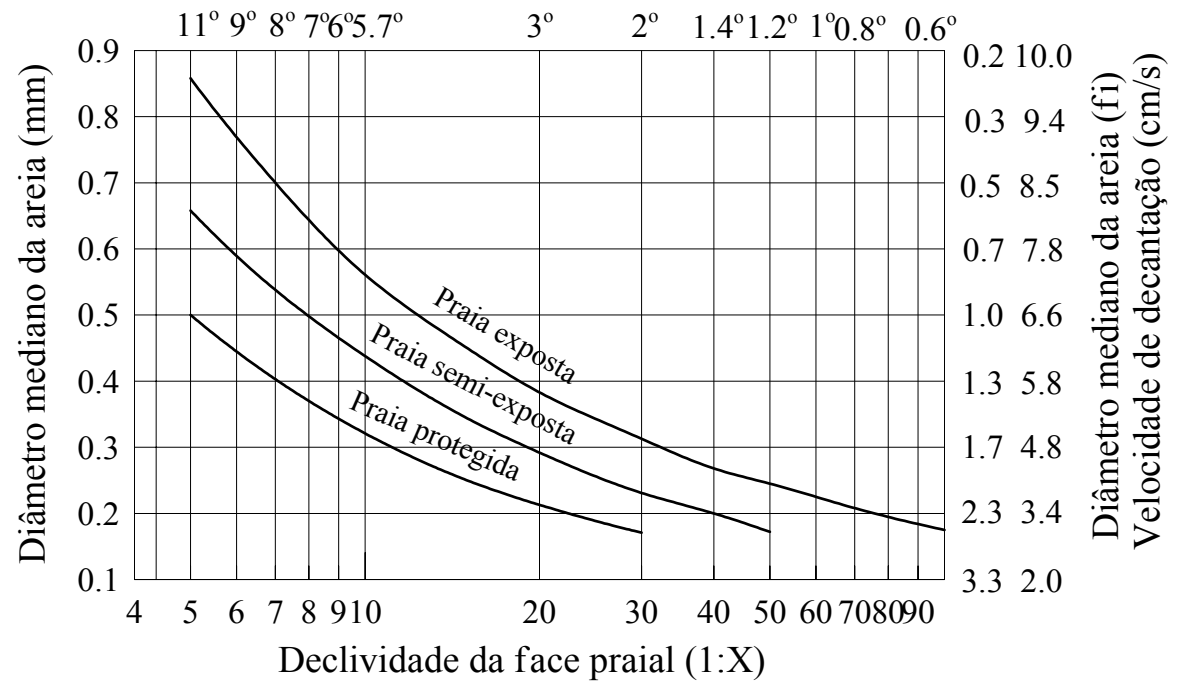

Fig. 1. Correlação entre a declividade da face praial e a característica granulométrica dos sedimentos em função da exposição às ondas (adaptado de Wiegel, 1964).

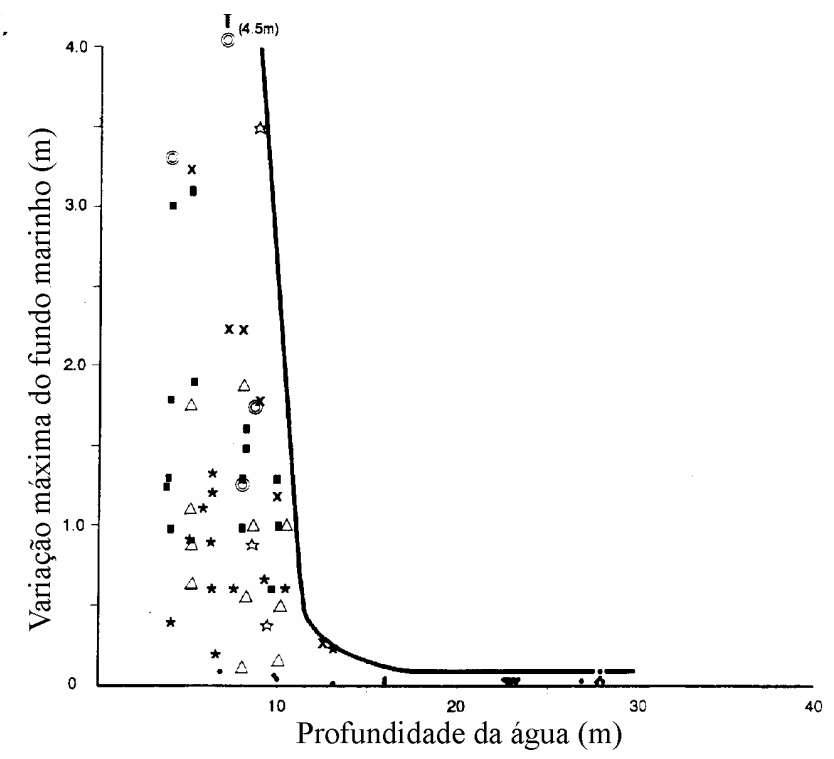

Fig. 2. Correlação entre variabilidade topográfica do fundo marinho e profundidade da água em antepraias da Austrália, Nova Zelândia e Dinamarca segundo Hesp e Hilton 1996.

ondas $(\mathrm{m})$

$\overline{H_{s}}=$ altura média significativa anual das significativas

$\sigma=$ desvio padrão anual das ondas

Nicholls et al. (1995) adotam um coeficiente de 1,75 para ajustar o valor de $\mathrm{d}_{1,1}$ a um período de 100 anos. Assim,

$d_{l, 100}=1,75 d_{l, 1}$
A utilização dos dois limites permite estabelecer uma faixa de profundidade mínima e máxima para a profundidade de fechamento do perfil de praia.

Cálculos da profundidade $d_{1,1}$ de fechamento do perfil, realizados para várias localidades da costa atlântica dos Estados Unidos, tiveram como resultado profundidades entre 5,4 e 7,4 m utilizando estatísticas de ondas baseadas em observações visuais, e entre 4,7 e $7,9 \mathrm{~m}$ a partir de altura de ondas medidas por ondógrafos (Hallermeier (1981). Para o litoral brasileiro os resultados obtidos a partir da obtenção dados de onda medidos por ondógrafos e observações visuais, dispersos ao longo de vários pontos da linha de costa, 
deram como resultado uma altura média significativa das ondas de $1,2 \mathrm{~m}$ e desvio padrão de $0,38 \mathrm{~m}$ resultando em profundidades médias de fechamento do perfil de $6,5 \mathrm{~m}$ e $11,4 \mathrm{~m}$ para respectivamente $\mathrm{d}_{1,1} \mathrm{e}$ $\mathrm{d}_{1,100}$. Em termos práticos foi estabelecido, para fins do exercício proposto, uma altura significativa média das ondas de $1,25 \mathrm{~m}$ e um desvio padrão de $0,4 \mathrm{~m}$.

\section{Resposta da Linha de Costa a uma Elevação do Nível do Mar}

Em direção à retroterra, o limite da praia é extremamente reduzido, principalmente se considerarmos um cenário de elevação do nível do mar. A definição de um limite mais interiorizado deverá pois considerar dois aspectos: o do alcance do processo morfodinâmico atual, a tendência erosiva baseado em taxas de erosão anual e que expressem uma tendência pelo menos decadal e o efeito de uma elevação do nível do mar. O limite dinâmico da praia sub-aérea será o do alcance máximo do processo deposicional de sedimentos provenientes da praia, independentemente de o processo ser por ação das ondas ou do vento. No primeiro caso o limite será a porção mais interiorizada da berma mais elevada ou, no caso de cordões litorâneos, ilhas barreira ou pontais submetidos a transposição por ondas (overwash), o limite do reverso dessas feições. No segundo caso, o do transporte eólico, o limite será a base do flanco reverso das dunas frontais.

Para a definição do limite em função de uma elevação do nível do mar, poderá ser adotado o cenário mais pessimista elaborado pelo Intergovernmental Panel of Climate Change (IPCC), o de uma elevação de $1 \mathrm{~m}$, até o ano 2.100 , devendo a faixa de absorção desse impacto ser estabelecida no sentido de evitar a perda de propriedades em função desta elevação. Mesmo que esse cenário não venha a se concretizar até aquela data, conforme sugerem as projeções mais recentes, a adoção de uma elevação de $1 \mathrm{~m}$ ainda é bastante razoável, considerando o elevado grau de incerteza relativo às tendências climáticas de longo prazo.

O ajustamento de uma linha de costa, a uma elevação do nível do mar, depende das características geomorfológicas e petrográficas da mesma, podendo os efeitos variar entre nenhum (costão rochoso), erosão (praias arenosas, falésias sedimentares) e inundação (áreas baixas freqüentemente ocupadas por manguezais ou marismas).

\section{Praias Arenosas}

A determinação da largura da faixa de segurança em praias, considerando apenas os efeitos de uma elevação do nível do mar, pode ser feita através da aplicação da lei de Bruun (Bruun, 1962), utilizando a equação:

$$
R=\frac{S L G}{H}
$$

onde:

$R=$ recuo erosivo da linha de costa devida à elevação do nível do mar (m)

$S=$ elevação do nível do mar (m)

$L=$ comprimento do perfil ativo (m)

$H=$ altura do perfil ativo (m)

$G=$ Proporção de material erodido que se mantém no perfil ativo

A altura do perfil ativo $(H)$ pode ser determinada pela somatória da altura da feição emersa ativa (topo do cordão litorâneo, altura da duna frontal etc.) com a profundidade de fechamento do perfil $\left(\mathrm{d}_{1,1}\right.$ ou $\mathrm{d}_{1,100}$ ), sendo $L$ a distância horizontal entre a elevação máxima do perfil ativo e a profundidade de fechamento.

\section{Determinação da Distância entre a Linha de Costa e a Profundidade de Fechamento do Perfil}

A partir de dados encontrados na literatura e de informações verbais foi adotado para a altitude da orla, um valor médio de $6 \mathrm{~m}$ para o litoral a norte do cabo Frio, até ao Amapá e de $7 \mathrm{~m}$ para o restante do litoral Sudeste e Sul.

Para a determinação da largura do perfil ativo (distância da costa à profundidade de fechamento do perfil) foram utilizadas as cartas náuticas de escala aproximada de 1:300.000. Os pontos de medição foram escolhidos com a utilização do Guia de Praias da Quatro Rodas para a localização das praias consideradas significativas. Ao todo foram medidas 143 posições. Como a carta náutica, na escala disponível, não permite a determinação razoavelmente precisa das profundidades calculadas para o fechamento do perfil, utilizou-se as isóbatas de $5 \mathrm{~m}$ e $10 \mathrm{~m}$ como limites oceânicos, para todo o litoral, o que é uma boa aproximação prática aos valores de $\mathrm{d}_{1,1}$ e $\mathrm{d}_{1,100}$ encontrados

$O$ resultado obtido evidencia que a maior parte da plataforma continental interna brasileira apresenta declividades muito baixas (inferiores a $0,2^{\circ}$ como média geral), típicas de plataformas continentais passivas, como do litoral atlântico dos Estados Unidos, Golfo do México e Sudeste da Austrália (Figura. 3).

Em conseqüência a retrogradação da linha de costa atinge teoricamente centenas de metros nas declividades mais baixas (Tabela 1).

A constatação acima confere com o resultado de modelagem apresentada em Roy et al. (1994) conforme gráfico da figura 4 , onde se observa que a típica retrogradação de $50 \mathrm{~m}$, freqüentemente mencionada na literatura como resposta a uma elevação de $1 \mathrm{~m}$ do nível do mar, se limita a declividades em torno de $1^{\circ}$ mais comumente encontradas nas regiões 
Sul e Sudeste e em pontos isolados do litoral nordestino.

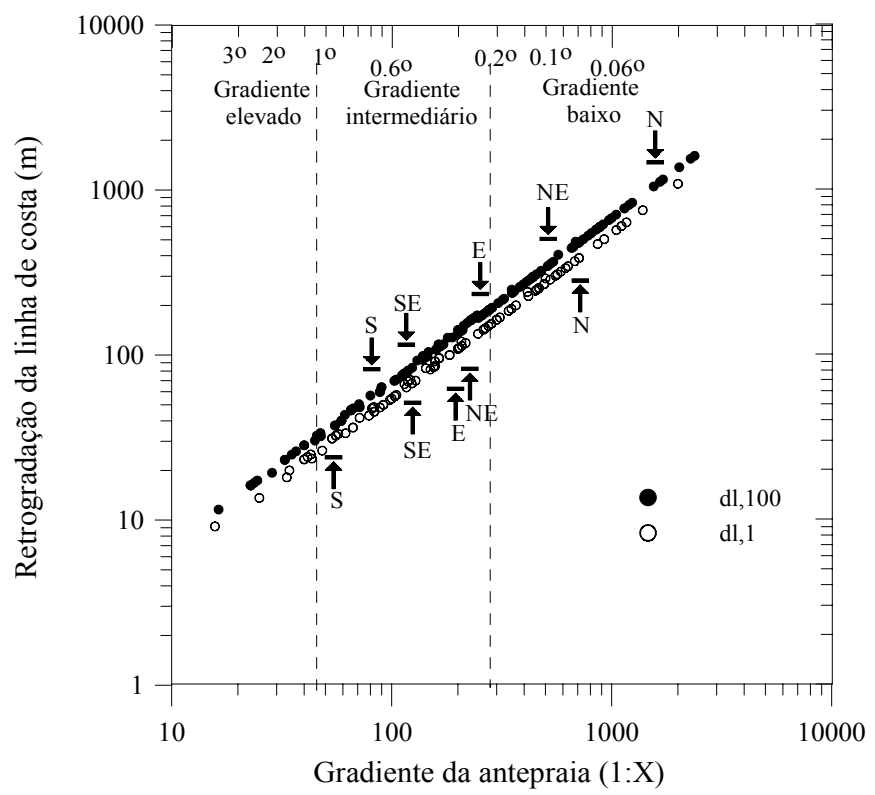

Fig. 3. Retrogradação da linha de costa em resposta a uma elevação de $1 \mathrm{~m}$ do nível relativo do mar e profundidade de fechamento de $5 \mathrm{~m}\left(\mathrm{~d}_{\mathrm{l}, 1}\right)$ e $10 \mathrm{~m}\left(\mathrm{~d}_{\mathrm{l}, 100}\right)$

Tabela 1. Retrogradação em função da declividades médias da antepraia por região para uma elevação de $1 \mathrm{~m}$ do nível relativo do mar

\begin{tabular}{lccrrrr}
\hline Região & \multicolumn{2}{c}{ Retrogradação $(\mathrm{m})$} & \multicolumn{2}{c}{ Gradiente $(1: \mathrm{X}$} & \multicolumn{2}{c}{ Declividade (graus) } \\
& $\mathrm{d}_{1,1}$ & $\mathrm{~d}_{1,100}$ & $\mathrm{~d}_{1,1}$ & $\mathrm{~d}_{1,100}$ & $\mathrm{~d}_{1,1}$ & $\mathrm{~d}_{1,100}$ \\
\hline Norte & 290 & 894 & 533 & 1320 & 0,11 & 0,04 \\
Nordeste & 121 & 210 & 222 & 310 & 0,23 & 0,18 \\
Leste & 103 & 175 & 189 & 259 & 0,30 & 0,22 \\
Sudeste & 94 & 91 & 161 & 128 & 0,35 & 0,44 \\
Sul & 34 & 53 & 58 & 75 & 0.98 & 0,76 \\
\hline Média & $\mathbf{1 6 7}$ & $\mathbf{2 7 3}$ & $\mathbf{2 9 5}$ & $\mathbf{4 0 1}$ & $\mathbf{0 , 1 9}$ & $\mathbf{0 , 1 4}$ \\
\hline
\end{tabular}

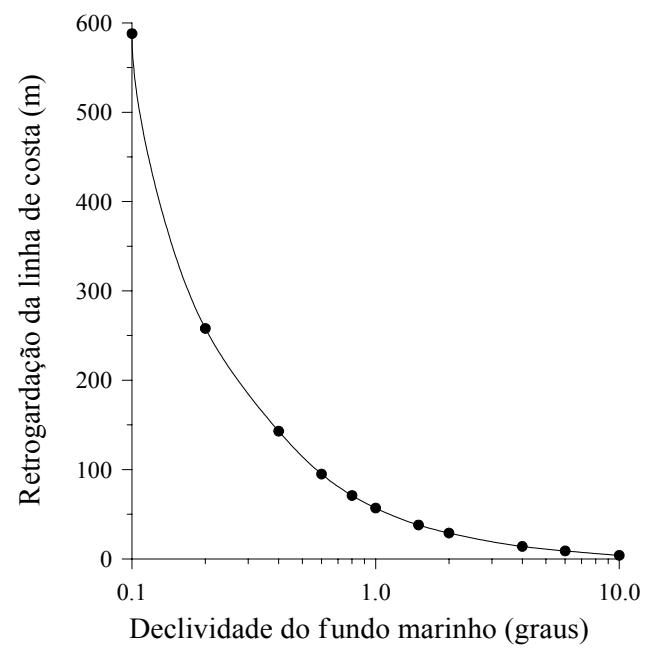

Fig. 4. Retrogradação da linha de costa em função da declividade do fundo marinho segundo modelo de Roy et al. (1994). 
Inundação (Praias lamosas/planícies de maré, Manguezais, Marismas)

Para praias lamosas ou planícies de maré, a equação (3) não pode ser adotada, pois a retrogradação tenderia ao infinito, devido à não permanência dos sedimentos erodidos no perfil e o baixo gradiente topográfico. Neste caso se aplica o modelo de inundação, devendo-se estabelecer uma faixa de proteção cuja largura é definida por um limite determinado numa cota $1 \mathrm{~m}$ acima do limite atual da área alcançada pela água.

\section{Erosão - Falésias em Rochas Sedimentares e Outras Rochas Friáveis}

No caso de falésias em rochas sedimentares, como ocorre no contato do Grupo Barreiras com o mar, a aplicação da equação (3) se torna difícil, tanto pelo longo lapso de reação ao processo erosivo, quanto pela elevada quantidade de sedimentos liberados, fazendo com que a retrogradação seja freqüentemente muito pequena. Esta tende a ser maior e com resposta mais rápida em falésias baixas de sedimentos pouco consolidados. Em geral as taxas de erosão são tão pequenas que se torna sem sentido calcular teóricamente as mesmas. O ideal é analisar a situação caso a caso, considerando a posição de testemunhos deixados pela retrogradação, registros fotográficos e iniciando, sempre que possível, um monitoramento das falésias ativas para determinar na prática a taxa de retrogradação. Esta taxa, quando adequadamente definida, isto é, para um período suficientemente longo para caracterizar uma tendência, deverá ser incorporada na fixação da largura de proteção da orla.

Um caso especial é representado pelos costões e falésias formadas em rochas duras do embasamento e que não respondem, em termos de erosão, a uma elevação do nível do mar, isto considerando uma escala de tempo compatível com o planejamento do uso do solo. Sob este aspecto, os mesmos podem ser considerados estáveis, devendo sua ocupação, quando previsto num plano diretor ou não impedida por legislação específica, ser orientada em função da exposição e, conseqüentemente, do alcance máximo das ondas acrescido de pelo menos mais $1 \mathrm{~m}$ acima deste alcance atual.

\section{Definição da Largura da Zona de Proteção}

As baixas declividades do fundo marinho que caracterizam, a maior parte do litoral brasileiro, constituem uma indicação de potencial fragilidade frente a uma elevação do nível do mar. No entanto, algumas características do litoral constituem elementos que não permitem uma simples aplicação do modelo de Bruun. Primeiramente, o litoral norte, com suas amplas áreas de manguezais associadas a planícies de maré, se enquadra mais num modelo de inundação do que de retrogradação. Além disto são áreas praticamente desabitadas. O Nordeste, Leste e parte do Sudeste, apresentam grandes extensões da orla com terrenos sedimentares elevados (Grupo Barreiras) que formam falésias junto ao litoral e cuja adaptação erosiva a uma elevação do nível do mar se faz a taxas que dependem da resistência ou coesão dos sedimentos, que por sua vez, ao serem disponibilizados, tendem a reduzir a amplitude da retrogradação. A ocorrência, quase contínua, de recifes (arenitos de praia), formando verdadeiros quebra-mares, principalmente entre Natal e Maceió, representa outra feição de proteção ao dissipar parte da energia das ondas. Um estudo realizado para a praia da Boa Viagem em Recife, (Bragard 1991, apud Neves e Muehe 1995), chegou, considerando uma elevação de $1 \mathrm{~m}$ do nível do mar e ondas com altura de $1 \mathrm{~m}$ na arrebentação, a uma retrogradação da linha de costa de apenas $21 \mathrm{~m}$. Menos, portanto, da metade dos típicos $50 \mathrm{~m}$ da literatura e menos ainda dos quase 150 $\mathrm{m}$ estimados em função da declividade do fundo marinho para esta área. Não obstante, esta ordem de grandeza é suficiente para alcançar os prédios mais próximos da orla. Uma terceira característica de proteção parcial da linha de costa é constituída pela superfície de abrasão submarina resultante da retrogradação dos depósitos sedimentares do Barreiras, que em algumas áreas se apresenta muito rasa e profusamente coberta por resíduos lateríticos, como no litoral central do Espírito Santo e norte do estado do Rio de Janeiro entre os rios Itabapoana e Paraíba do Sul, provocando uma tal perda de energia das ondas que as praias se apresentam praticamente protegidas.

Há portanto uma série de situações que modificam substancialmente os resultados da aplicação do modelo de Bruun, que entretanto pode servir para a fixação de um limite mínimo de proteção da orla, dependendo das características locais a alteração deste limite. Nesse sentido, um aspecto fundamental para a fixação da largura da zona de proteção para além do limite mínimo é a determinação da tendência evolutiva do litoral, tanto numa escala de tempo geomorfológica (centenas a milhares de anos) quanto na escala de tempo do processo atual (anos e décadas). A primeira serve para se ter uma idéia da tendência evolutiva histórica, com a identificação de áreas tradicionalmente frágeis, enquanto a segunda tem como função a identificação de áreas de feições costeiras intrinsecamente instáveis, nas quais a construção de residências ou outras construções permanentes deve ser inibida como na proximidade de desembocaduras fluviais, pontais, cordões litorâneos transgressivos, isto é sob efeito de transposição das ondas, entre outras, e, ainda a identificação de áreas com balanço sedimentar negativo, determinação de taxas de erosão e progradação e localização de pontos de convergência de energia das ondas. Portanto, a definição da largura da faixa de proteção é um processo dinâmico, variável no 
tempo, devendo ser modificável e se fundamentar na aquisição de conhecimento através da pesquisa geológica, geomorfológica e oceanográfica acrescida de monitoramento topográfico contínuo de pontos criteriosamente selecionados do litoral. A elaboração do Atlas de Erosão e Progradação do Litoral Brasileiro, em fase conclusão pelos grupos de pesquisa associados ao Programa de Geologia e Geofísica Marinha (PGGM) constitui um passo fundamental para a identificação de setores a serem monitorados.

\section{Proposta de Definição dos Limites Submarino e Terrestres da Orla}

Considerando os aspectos descritos acima e buscando uma convergência entre o estabelecimento de uma faixa mínima de proteção e de manutenção da estética da paisagem são propostos os seguintes limites mínimos para a orla conforme descrição abaixo e esquema da figura 5 :

Zona submarina: Isóbata de $10 \mathrm{~m}$ podendo ser modificado desde que, no caso de redução da profundidade, haja um estudo ambiental comprovando a localização do limite de fechamento do perfil em profundidades menores;

Orla terrestre urbanizada: Limite de $50 \mathrm{~m}$ contado a partir do limite da praia (conforme definido na Lei 7.661/88) ou a partir da base do reverso da duna frontal, quando existente;

Orla terrestre não urbanizada: Limite de $200 \mathrm{~m}$ contado a partir do limite da praia ou a partir da base do reverso da duna frontal, quando existente;

Falésias sedimentares: Limite $50 \mathrm{~m}$ a partir da borda da falésia; em lagunas ou lagoas costeiras $50 \mathrm{~m}$ contados a partir do limite da praia ou da borda superior da margem; em estuários $50 \mathrm{~m}$ contados a partir do limite da praia ou da borda superior em ambas as margens e ao longo das mesmas até onde cessa a penetração da água do mar.

Falésias ou costões em rochas duras: Limite a ser definido segundo plano diretor do município, estabelecendo uma faixa de segurança de pelo menos $1 \mathrm{~m}$ acima do limite máximo de ação das ondas de tempestade;

Áreas inundáveis: Limite definido por uma isolinha localizada a uma cota de pelo menos $1 \mathrm{~m}$ acima do limite da área atualmente alcançada pela preamar de sizígia.
Restrições: A construção de imóveis sobre substrato sedimentar como cordões litorâneos, ilhas barreira ou pontais com largura inferior a $150 \mathrm{~m}$ deve ser evitada devido ao risco de erosão e transposição pelas ondas, já que esta largura é insuficiente para estabelecimento de uma faixa de proteção capaz de absorver os efeitos de uma elevação do nível relativo do mar ou de efeitos decorrentes de um balanço sedimentar negativo. Áreas próximas a desembocaduras fluviais também apresentam riscos de erosão associados à própria instabilidade das mesmas. A definição da extensão destas zonas de não ocupação deve ser feita a partir do conhecimento de eventos erosivos pretéritos ou através de estudos específicos de evolução costeira.

Os limites máximos estabelecidos para a orla (200 metros de distância a partir do limite da praia ou do reverso da duna frontal e 10 metros de profundidade) deverão ser modificados para mais sempre que existam dados indicando uma tendência decadal de taxas de erosão anual capaz de ultrapassar rapidamente a largura da faixa de proteção estabelecida. A prática adotada na Carolina do Norte (EUA) para a construção de casas é a de acrescentar ao limite da praia uma largura de 30 vezes a taxa de erosão anual e no caso de construções mais pesados, como edifícios, uma largura igual a 60 vezes a taxa de erosão anual ou uma largura de 30 vezes a taxa de erosão anual acrescido de uma distância fixa de $32 \mathrm{~m}$, sendo adotada a distância que for menor entre as duas opções (North Carolina 1985 apud CicinSain e Knecht 1998).

A diminuição dos limites mínimos poderá ocorrer quando houver tendência progradacional da linha de costa, também expressa em taxas anuais ou o local se situar em áreas abrigadas, desde que justificado tecnicamente, sem prejuízo da competência estadual ou municipal para estabelecer medidas mais restritivas.

\section{Considerações Finais}

Os limites propostos para zona de proteção representam um compromisso entre o desejável e o possível, já que, principalmente nas áreas urbanas, faixas de largura ainda maiores que a proposta, embora preferíveis, teriam sua implantação frustrada por simples desobediência e dificuldade de fiscalização.

Um exemplo quase ideal é o da Turquia (Fig. 6) que fixou uma largura mínima de $50 \mathrm{~m}$, após o limite da praia, na qual não é permitido o estabelecimento de construções, a não ser as de uso público ou de infra-estrutura. Uma segunda faixa, mais interiorizada, é destinada à circulação e a obras de saneamento, infra-estrutura, recreação e turismo. No total a faixa de segurança é igual ou superior a $100 \mathrm{~m}$ medidos a partir do limite proximal da praia, ou seja do contato da berma coma área estável, geralmente vegetada, não incluída no perfil dinâmico da praia. 


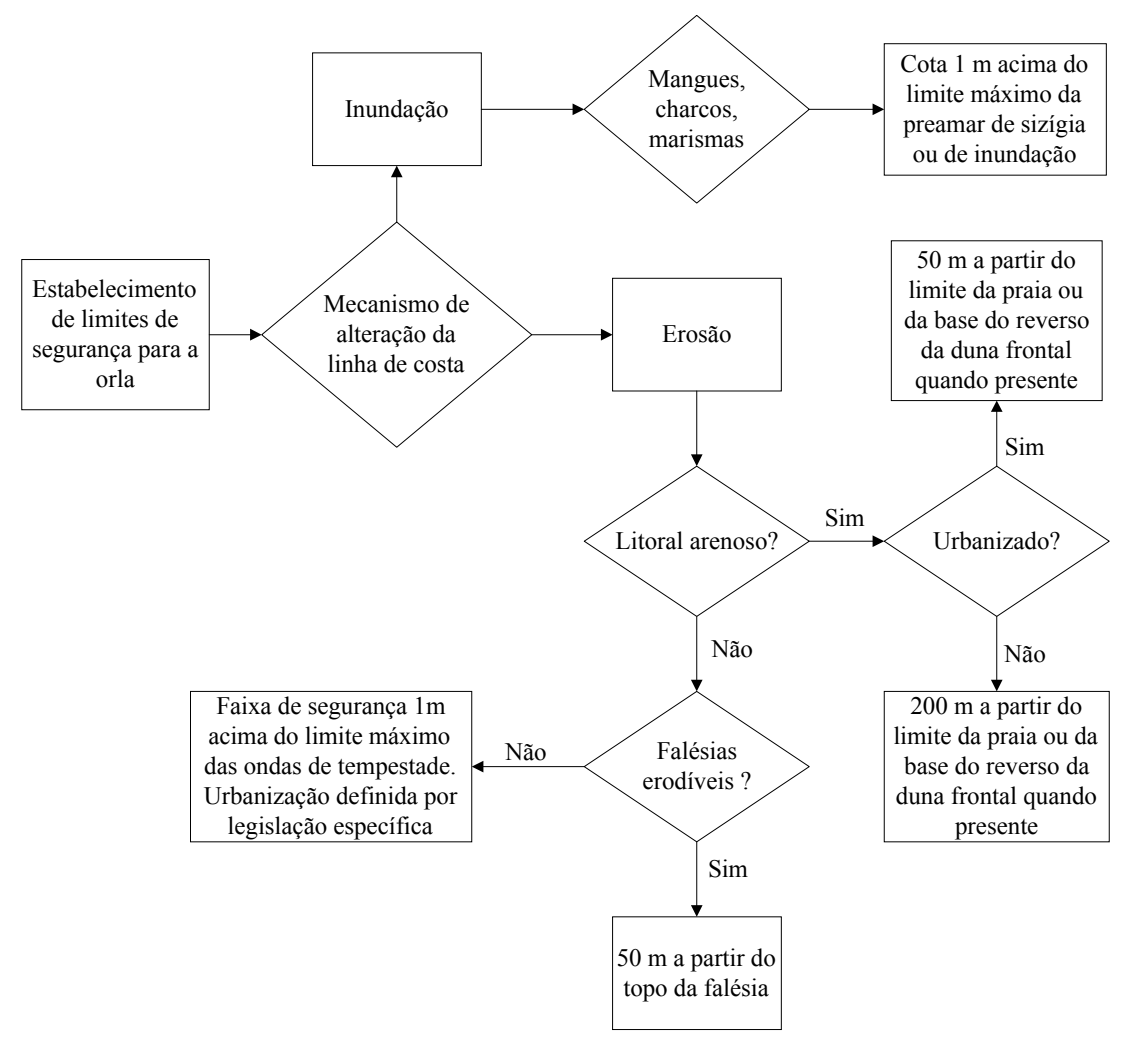

Fig. 5. Limites mínimos da orla segundo as características morfológicas do litoral

Comparado a outros países estaria o Brasil aderindo a uma tendência que é a de fixação de faixas com largura entre 100 e $200 \mathrm{~m}$ conforme mostra a figura 7, chegando a $500 \mathrm{~m}$ como na Grécia. Colômbia, Costa Rica, Indonésia e Venezuela adotam 50 m. A França, Noruega, Suécia e Turquia adotam o

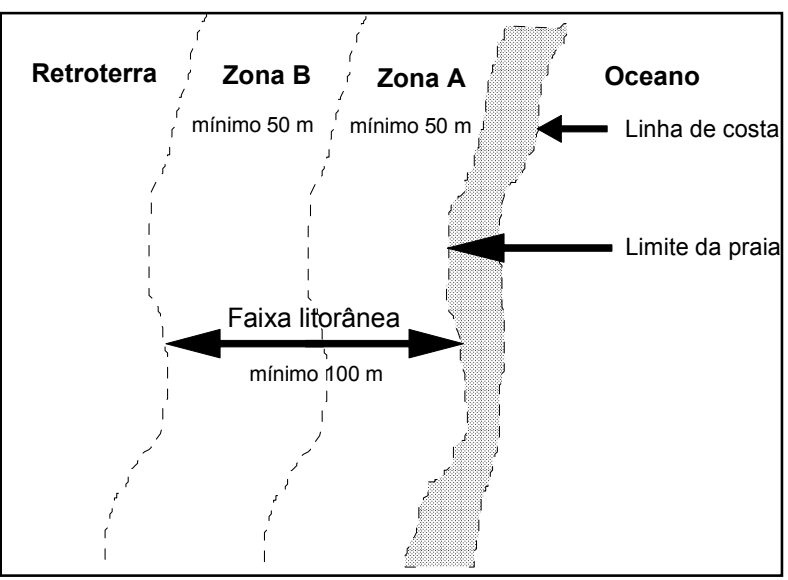

limite de 100 m. Espanha 100 a 200 m, Costa Rica 50 a $200 \mathrm{~m}$, Uruguai $250 \mathrm{~m}$. Limites ainda mais largos são adotados por alguns países para restrições específicas, como instalação de novas indústrias, proteção de manguezais, proibição de construção de casas de veraneio (Clark 1995).

Fig. 6. Definição de faixas de zoneamento costeiro na Turquia (segundo legislação de abril de 1990 e julho de 1992 modificado de Cicin-Sain e Knecht 1998)

Praia: Proibida a escavação ou dragagem que possa provocar alterações na praia. Permissão terá que ser requerida para obras de infra-estrutura como cais, portos, pontes, faróis, quebramares etc. e que poderão afetar a proteção da praia ou o uso pela população.

Zona A: Excetuando as obras que possam ser implantadas conforme descrito para a faixa de praia, não poderão ser erguidas quaisquer outras construções. A faixa se destina exclusivamente a pedestres e para recreação.

Zona B: Compreende o restante da faixa litorânea, tendo largura de pelo menos $50 \mathrm{~m}$. Pode conter estradas além de instalações para recreação e turismo para uso público. Instalações públicas para tratamento de esgoto poderão ser construídas nesta faixa desde que autorizado. 


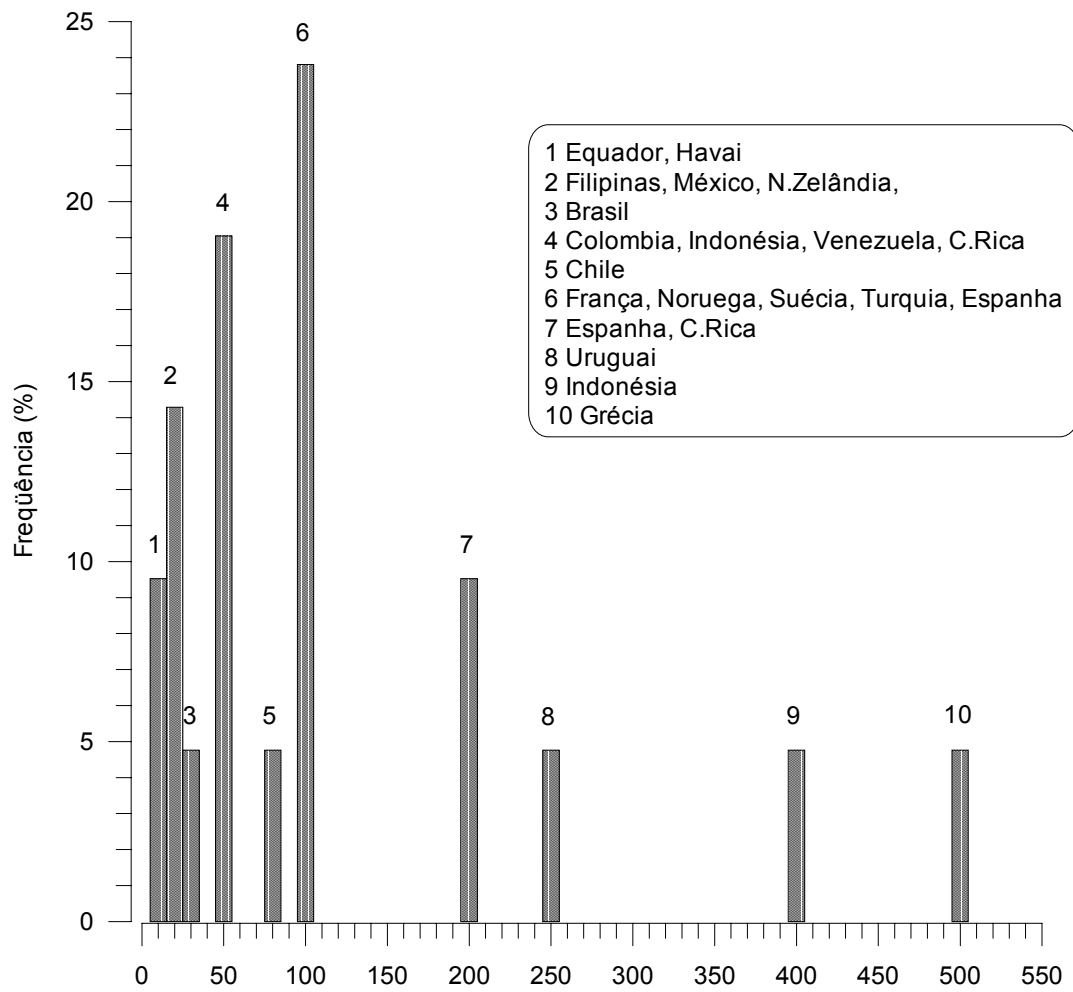

Fig. 7. Freqüência relativa, considerando o conjunto de países analisados, da largura (em metros) da zona de proteção ou uso restrito medida a partir da preamar média de sizígia (Fonte: Sorensen et al. 1992).

\section{Bibliografia}

Bragard, A. S. (1991) A influência da elevação do nivel do mar sobre os processos litorâneos em Recife. Monografia. Departamento de Hidráulica e Saneamento, Universidade Federal do Rio de Janeiro. 95p.

Bruun, P. (1962) Sea level rise as a cause of shore erosion. Journal of Waterway, Port, Coastal and Ocean Engineering, ASCE, 88, 117-130.

Bruun, P. (1988) The Bruun rule of erosion by sealevel rise: a discussion on large-scale two- and three - dimensional usages. Journal of Coastal Research, 4(4):627-648.

Cicin-Sain, B. e Knecht, R.W. (1998) Integrated coastal and ocean management. Concepts and practices. Island Press. 517p.

Hallermeier, R.J. (1981) A profile zonation for seasonal sand beaches from wave climate. Coastal Engineering, 4:253-277.

Hesp, P. e Hilton, M.J. (1996) Nearshore-surfzone system limits and the impacts of sand extraction. Journal of Coastal Research, 12(3):726-747.
IPCC (Intergovernmental Pannel of Climate Changes) (1990) Policymakers summary of the scientific assessment of climate change. Report to IPCC from working group 1, second draft, ASCE, p.27.

Neves, C.F. e Muehe, D. (1995) Potential impact of sea-level rise on the metropolitan region of Recife, Brazil. Journal of Coastal Research, SI, 14:116-131.

Nicholls, R.J., Dennis, K.C., Volonté, C.R. e Leatherman, S.P. (1993) Methods and problems in assessing the impacts of accelerated sea-level rise. In: Bras, R. (ed.), The world at-risk: natural hazards and climate change, AIP Conference Proceedings, American Institute of Physics, New York, 193-205.

Nicholls.R.J., Leatherman, S.P., Dennis, K.C. e Volonté, C.R. (1995) Impacts and responses to sea-level rise: qualitative and quantitative assessments. Journal of Coastal Research, SI. 14:26-43. 
Roy, P.S., Cowell, P.J., Ferland, M.A. e Thom, B.G. (1994) Wave-dominated coasts. In: Carter, R.W.G e Woodroffe, C.D. (ed.). Coastal evolution - late quaternary morphodynamics. p.121-186. Cambridge University Press.

Sorensen, J.C., McCreary, S.T e Brandani, A. (1992) Costas - Arreglios Institucionales para manejar ambientes y recursos costeros. Centro de Recursos Costeros. Universidad de Rhode Island. 185p.

Worldwatch, (2000) Melting of earth's ice cover reaches new high - a WWI News Brief. http://.worldwatch.org/alerts/000306.html. 